\title{
Chapter 11 \\ Rice Straw Value Chains and Case Study on Straw Mushroom in Vietnam's Mekong River Delta
}

\author{
Matty Demont, Thi Thanh Truc Ngo, Nguyen Van Hung, \\ Giang Phuong Duong, Toàn Minh Dưong, Hinh The Nguyen, \\ Ninh Thai Hoang, Marie Claire Custodio, Reianne Quilloy, \\ and Martin Gummert
}

\begin{abstract}
Rice straw is a tradable commodity in food and feed markets, particularly in rice-producing countries such as India, Vietnam, and Cambodia. Understanding the bottlenecks and linkages of different components and actors in rice and rice straw value chains is important to identify strategies to extract maximum value out of the straw and encourage diversion of straw utilization from unsustainable practices, such as burning, to more sustainable uses of rice straw. In Vietnam, for example, demand for mushroom and dairy products generate a market for high-quality straw, which can be an input for both industries. Mechanized straw collection is critical to supplying the byproduct as an input for these markets. Generally, the successful development of rice straw value chains will hinge on investments in intersectoral upgrading, triggered by the demand for food, feed, energy, and fiber from a growing urban population and the expanding food and nonfood industries. This chapter provides: (1) an overview of rice straw value chains, (2) a case study of rice straw mushroom value chains in Vietnam, and (3) suggestions for further developments.
\end{abstract}

\footnotetext{
M. Demont $(\triangle) \cdot$ N. V. Hung $\cdot$ M. C. Custodio $\cdot$ R. Quilloy $\cdot$ M. Gummert International Rice Research Institute (IRRI), Los Baños, Laguna, Philippines e-mail: m.demont@irri.org; hung.nguyen@irri.org; m.custodio@irri.org; r.quilloy@irri.org; m.gummert@irri.org

T. T. T. Ngo $\cdot$ T. M. Dương

Can Tho University, Can Tho, Vietnam

e-mail:ntttruc@ctu.edu.vn

G. P. Duong

Food and Agriculture Organization of the United Nations (FAO), Rome, Italy

H. T. Nguyen · N. T. Hoang

Ministry of Agriculture and Rural Development (MARD), Hanoi, Vietnam
} 
Keywords Rice straw · Value chain · Intersectoral upgrading · Straw mushroom • Vietnam

\subsection{Introduction}

Value chains are by definition demand-driven (FAO 2014; Kaplinsky and Morris 2000). However, rice straw value chains - straw being a byproduct of rice value chains - are supply-driven rather than demand-driven. Rice straw is produced to satisfy the demand, not for rice straw but for rice, which drives rice value chain operations, from which rice straw is generated. This generation of the straw, in turn, triggers the need for proper use and management of the byproduct and, thus, the evolvement of straw supply chains. The demand for rice straw products in diverse markets will not necessarily trigger the production of the straw-as in a classic value chain - but will rather encourage the diversion of straw utilization from one activity (e.g., burning, incorporation) to another (e.g., baling, selling). The notion of an "end-market" is central to food value chain research (FAO 2014). In the case of rice straw value chains, the end-product is not food for human, but animal feed or an input into other food or nonfood value chains (e.g., dairy, meat, mushroom, energy, fiber, etc.). As a result, the "end-markets" for rice straw value chains are generally input markets for other food or nonfood value chains.

Value chain development typically follows an upgrading trajectory, which begins with process upgrading, moves on to product upgrading, and then on to functional, channel and intersectoral upgrading (Gereffi 1999; Kaplinsky and Morris 2000). Value chain upgrading - from process up to intersectoral upgrading - is triggered by demand factors (e.g., increasing demand for organic products) and then operationalized and reinforced by supply factors in response to the changes in the demand side (e.g., farmers' adoption of organic farming and traders' assurance of product quality and traceability throughout subsequent value chain stages). Urbanization, rising income levels, and diet change drive up the demand for high-value food products (Wang et al. 2014) and trigger a shift in food expenditure components, with a decreasing share of rice and rising shares of meat/fish, vegetables, and edible oils (Reardon 2015). As a result, actors on the supply side of rice value chains increasingly explore ways to offer customers more attractive rice products with superior quality attributes in terms of fragrance, purity, homogeneity, packaging, food safety, traceability, nutrition, health, and convenience. Rice businesses increasingly compete not just on price but on quality and product differentiation (Reardon et al. 2014). This triggers investment in process upgrading (e.g., adoption of postharvest and processing technology, good agricultural practices), product upgrading (e.g., improvement of intrinsic quality and extrinsic quality cues such as packaging, branding, and advertising), and functional upgrading (e.g., millers taking on the role of prefinancing quality inputs for farmers through contract farming to ensure reli- 
able sourcing of quality paddy). Rising income levels also stimulate a shift towards consuming more processed products and prepared foods bought outside the home (Reardon et al. 2014; Reardon 2015). Together with the development of the industrial and manufacturing sectors and their concomitant demand for energy and fiber, this provides tremendous opportunities for intersectoral upgrading of rice value chains (Nguyen et al. 2017). Intersectoral upgrading of rice value chains may provide alternative income opportunities for value chain actors by diversification of incomegenerating activities and by adding value to existing rice products and/or byproducts (e.g., rice straw, rice husks, and rice bran). It also increases the sustainability of rice value chains by providing alternatives to existing unsustainable uses of byproducts, such as the burning of rice straw.

\subsection{Mapping Rice Straw Value Chains in Vietnam, Cambodia, and the Philippines}

Figure 11.1 shows a schematic diagram that maps rice straw value chains based on a multi-stakeholder workshop series conducted in Vietnam, Cambodia, and the Philippines under the BMZ-IRRI rice straw management project (IRRI 2019).

Rice straw value chains consist of three main functions: (1) harvesting, (2) collection and pretreatment, and (3) rice straw-based production and rice straw markets. It is worth noting again that, unlike food products whose end-markets are food consumers (via national and international food markets), rice straw generally ends up being used as an input for the production of other food and nonfood products. The end-markets of rice straw, as such, are often input markets. Currently, in the studied countries, rice straw is mainly used in the production of mushroom, ruminant feed, compost, mulching, and lining materials for the transportation of fragile fruits (e.g., watermelon) due to concrete, significant market demand for these strawbased products. Even though other new technologies and utilizations of rice straw (e.g., biochar, briquettes, bioenergy, biodegradable products, biofiber, etc.) are also already introduced, markets barely exist for these products (although they are emerging). Therefore, the markets for these relatively new straw-based products are categorized as "future markets".

The overall rice straw value chain process involves the collection of in-field rice straw and then transportation of the straw to end-users for their straw-based production activities. Specifically, rice straw that remains on the field after rice harvesting is collected, usually by contract service providers (who collect straw for a fee paid by rice farmers) or straw traders (who purchase in-field straw from farmers and then collect straw at their costs). Rice straw collection involves physical pretreatment of the straw, i.e., transforming straw that is spread around the field into various forms such as loose, baled, compacted, or chopped straw, depending on the specific subsequent uses. 


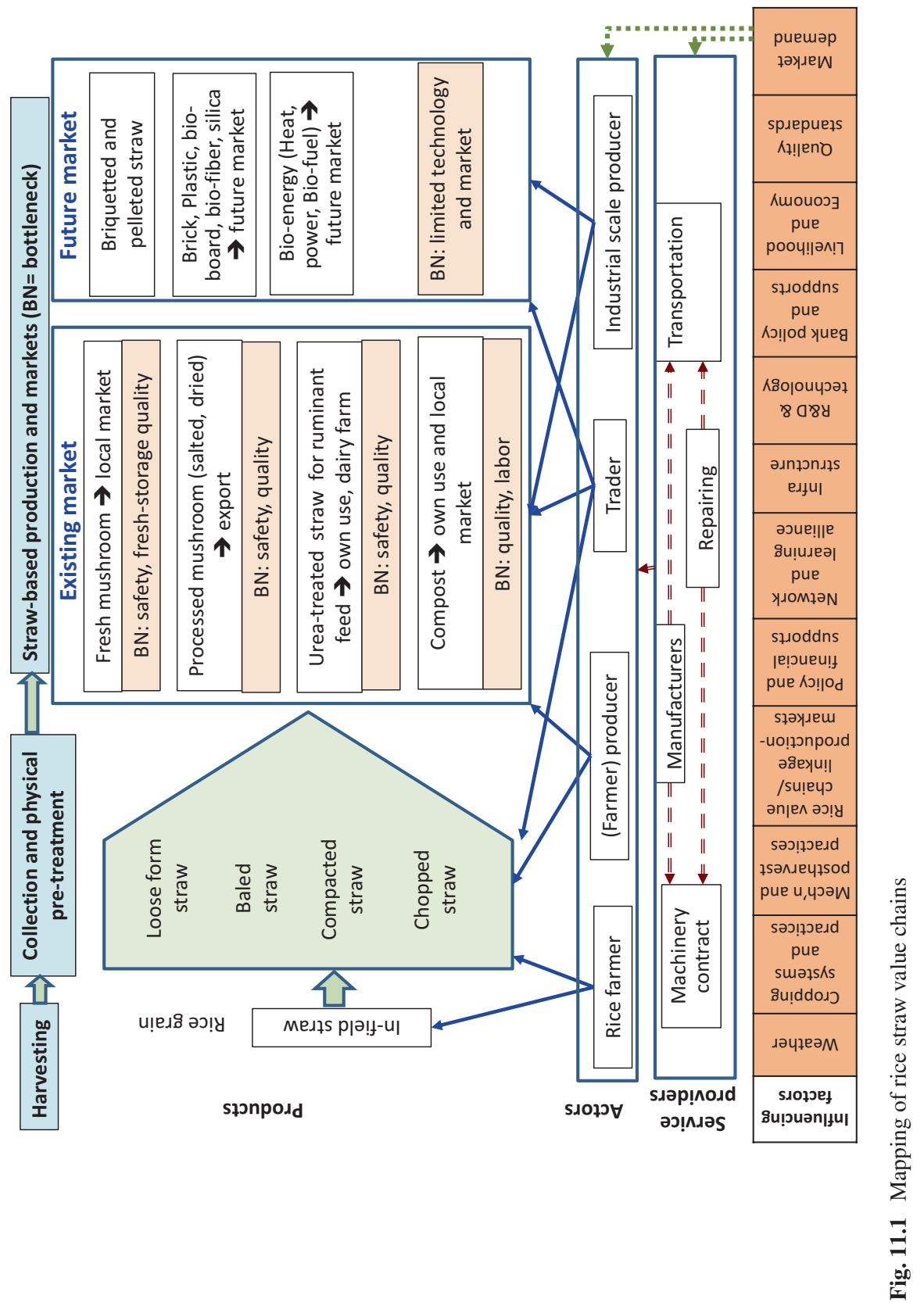


Rice straw value chains for the three countries are affected by many influencing factors, such as climate variability, rice variety, cropping systems employed, policies, technology availability, financial support systems, and extension systems.

\subsection{Case Study of Rice Straw Mushroom Value Chains in Vietnam's Mekong River Delta (MRD)}

\subsubsection{Mapping Value Chains}

Rice straw mushroom (Volvariella volvacea) (RSM) has been produced in the MRD for more than 20 years (Truc et al. 2013). However, the utilization of rice straw for mushroom production is still limited, using less than $5 \%$ of the total rice straw produced in the MRD. Can Tho City (CTC) and Dong Thap Province are most advanced in producing RSM. RSM is consumed both in fresh and processed forms, as illustrated through two channels targeting domestic markets and export markets (Fig. 11.2).

The domestic market of fresh mushroom mainly exists in the local areas, i.e., neighboring areas where mushroom farmers live. About $40-60 \%$ of this product is consumed in Ho Chi Minh City (HCMC), the largest city in the country with about 8.5 million residents, and nearby areas (100-300 km away).

As fresh mushroom can only be kept for 3 days (see Chap. 6), the amount (30-40\% of the total RSM produced) that remains after being supplied to the fresh markets are then processed for export to China, Taiwan, Hong Kong, United States, and Europe.

In the domestic market, end-consumers of fresh RSM are individual households and institutional buyers. They buy fresh RSM mainly in the traditional or local wet

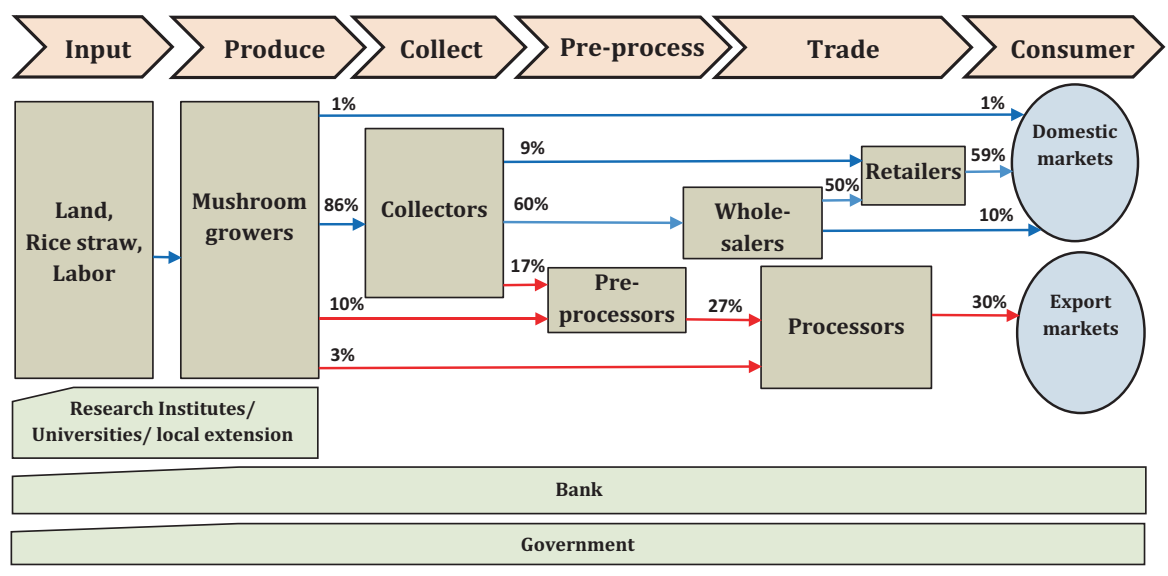

Fig. 11.2 RSM value chains in the MRD 
markets. Less than $5 \%$ of the fresh product is consumed through supermarkets in Vietnam. About 80 to $90 \%$ of the fresh product is consumed by individual households who source mushrooms from local wet markets and supermarkets. The remaining $10 \%$ to $20 \%$ of RSM are consumed by institutional buyers (including staff and student canteens) and in restaurants. Institutional mushroom consumers buy the fresh product from both wholesalers and retailers.

\subsubsection{Distributors}

These actors include mushroom collectors and transporters, wholesalers, and retailers. RSM distributed to HCMC and some nearby markets are collected by collectors or transporters at farms of the growers or at the CTC assembly market.

\subsubsection{Collectors and Transporters}

These actors buy fresh mushroom from the production sites of mushroom growers or at the assembly market; they then deliver the product to preprocessors. The raw and fresh RSM includes cleaned and boiled products.

\subsubsection{Pre-processors}

The main roles of these actors are to classify the RSM (if they buy fresh from the growers) and then boil and salt or brine it. They deliver salted RSM at different sizes or grades, depending on the processors' requirements. There are reportedly six preprocessors in CTC and more than 10 in Dong Thap Province. Pre-processors invest in equipment and materials and buy the mushroom fresh, especially when the price is low.

\subsubsection{Processors}

There are two main processing companies in the MRD including Tu Thao Ltd., located in Soc Trang Province, and Quoc Thao Ltd. located in Vinh Long province. Their processed-RSM products are mainly exported to Asia, United States, and Europe. Products for exporting need to meet the required safety criteria set by the export markets. 


\subsubsection{Wholesalers}

These actors are both primary wholesalers (big collectors near the production sites or assembly market) and secondary wholesalers in local markets in the MRD and wholesale markets in HCMC. Binh Dien wholesale market, one of the biggest wholesale markets in HCMC, consumes 50-60\% of the total fresh RSM produced in the MRD. Thus, they have an important role in setting the market price and shaping demand for fresh RSM in the MRD. Lack of proper transportation and improper storage, poor transportation systems, and prolonged travel time usually deteriorate the quality of mushrooms arriving in wholesale markets and retailer markets in the MRD and HCMC. As a result, wholesalers usually sell all fresh RSM within the day.

\subsubsection{Retailers}

Retailers buy fresh RSM from primary or secondary wholesalers or collectors. The retailers operate in both wet markets and supermarkets but they handle a much larger amount of RSM in the former. Retailers also sell different types of vegetables including RSM at their wet market outlets. One risk in mushroom trading is that all fresh mushrooms must be sold within a day of reaching the market since quality will be lost given the poor preservation conditions.

\subsubsection{Input Suppliers}

These actors mainly include rice straw and spore suppliers. Labor and land are major inputs for RSM production. Labor includes both permanent and seasonal workers. The mushrooms are grown on land owned by growers or rented from other villagers such as rice land, free spaces in fruit gardens, or unused land in the community.

\subsubsection{Rice Straw Collectors and Traders}

Rice straw is collected either mechanically or manually. Mechanized collection is a good business model recently developed in the MRD (Nguyen et al. 2016). However, there is still a poor match between rice straw suppliers and mushroom growers in terms of specific mushroom quality characteristics, such as nutrient content (straw collected right after harvest) and minimal contamination as mentioned in Chap. 6. 


\subsubsection{Spore Suppliers}

The spore business is generally a household enterprise. There are spore multipliers (suppliers) and spore agents. The agents buy spores from the suppliers who deliver them to the mushroom growers. There are perhaps as many as four spore suppliers in CTC and Dong Thap. They multiply spores (second or third generation) from pure spores. The challenges for suppliers are a general lack of (1) pure spore sources and (2) techniques to maintain spore quality, especially during the rainy season.

\subsubsection{RSM Production}

RSMs are produced by both rice farmers and mushroom growers. Some rice farmers make use of their own rice straw to produce the mushrooms. They often produce up to three mushroom cycles per year after harvesting rice. Mushroom growers are farmers who grow as many as six or seven RSM cycles annually. Outdoor mushroom growing (see Chap. 6) prevails in the area; little indoor growing is being done. Consumers prefer white-colored over dark-colored mushrooms. For producing white RSM, the growing beds require higher quantities of rice straw, which increases costs by $20-30 \%$.

\subsubsection{External Agents and Remaining Knowledge Gaps}

These actors include local authorities, extension specialists with the Department of Agricultural and Rural Development and universities who provide services by introducing improved RSM production practices, and other institutes that conduct research. In addition, banks give loans to mushroom growers and other agents of the mushroom subsectors. Unfortunately, the contributions of these enablers to the development of RSM value chains in CTC and Dong Thap are insignificant. Even though the central government has recently issued regulations to support this subsector, insufficient research is being conducted on RSM value chains.

Thus, knowledge gaps remain in terms of improving RSM productivity, adding value, enhancing spore production and mushroom storage systems, and developing new RSM products. Technology transfer, mainly from the government, is very slow due to the lack of finance and the resistance to change among mushroom growers and other agents in the RSM subsector.

\subsubsection{Economic Analysis}

Figure 11.3 visualizes the annual farm-gate price trend of fresh RSM sold at harvest to fresh and processed-RSM markets in the MRD in 2015-2016 (Truc et al. 2017). Farm-gate prices are unstable due to annual fluctuations in demand generated by 


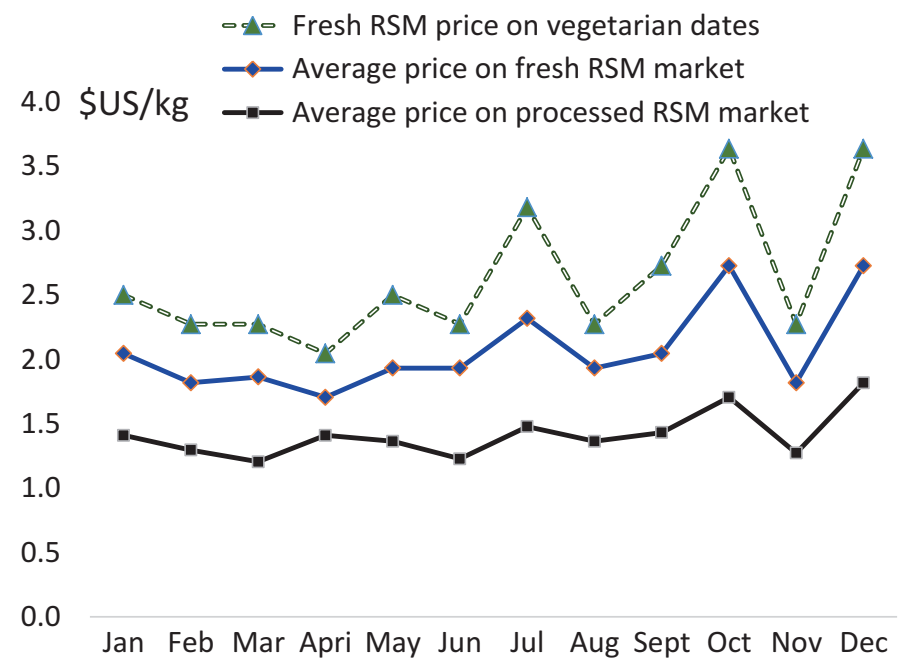

Fig. 11.3 RSM price at the farm-gate in the MRD in 2015-2016

vegetarian days and holidays, and because fresh mushrooms have to be sold within the day, as already explained.

The farm-gate price of fresh RSM on vegetarian days was about 2.0-3.6 \$US $\mathrm{kg}^{-1}(40-120 \%)$ higher than on non-vegetarian days. Fresh RSM for the processed market usually has lower quality in terms of color, maturity, and size compared to the fresh-RSM market, resulting in price discounts. In addition, the processed-RSM market usually supplies higher quantities on non- vegetarian days when the demand for fresh RSM is lower than on vegetarian days. The farm-gate price for processed RSM is much lower, ranging between 1.2 and $1.8 \$ \mathrm{US} \mathrm{kg}^{-1}$ on average. The demand for vegetarian food consumption is higher in July, October, and December, driving up the price of fresh RSM during these times.

The significant gap (1.5-2.8 times) between the prices on fresh-RSM and processed-RSM markets provides mushroom growers with an incentive to schedule their RSM growing and harvesting activities according to the demand on the freshRSM market. However, as the quality of fresh RSM can degrade rapidly, it can only be sold in the domestic market within a day. The unsold fresh RSM (about 30\% to $40 \%$ of total production) is then distributed to the companies that process and export the processed products.

Figures 11.4 and 11.5 visualize the value-added generated at different functions (stages) by the corresponding actors along the fresh and processed-RSM value chains and the selling prices of RSM at each stage. The value-added at a certain stage is the difference between the selling price (i.e., the price at which the product is sold to the actor of the next stage) and the intermediate costs (i.e., the cost of buying the product from the previous stage plus the cost of inputs incurred at this stage). 


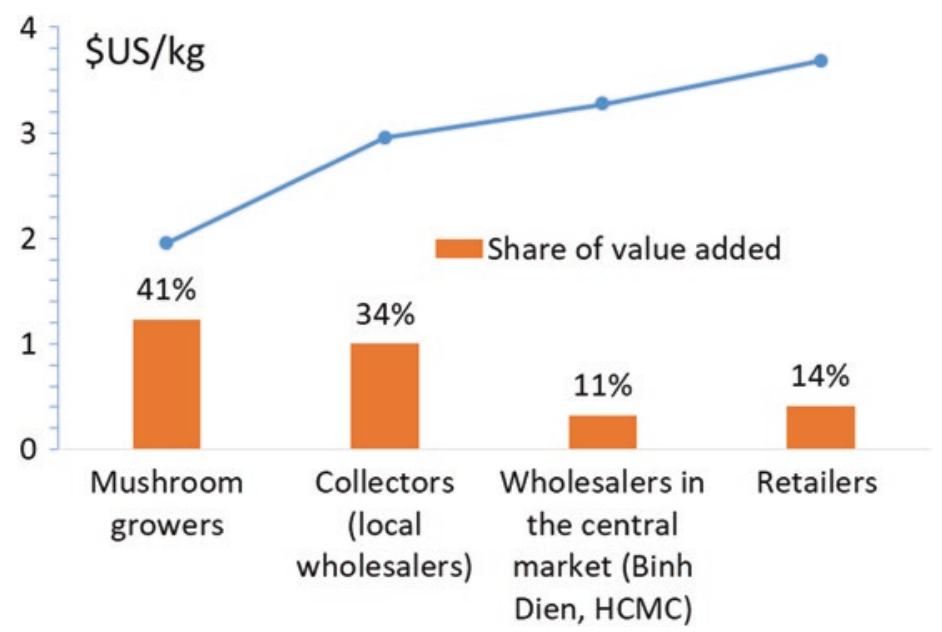

Fig. 11.4 Shares of value-added and selling prices by actors along fresh RSM value chains in MRD, Vietnam in 2015-2016. (Adapted from Toan (2018) and Truc et al. (2017))

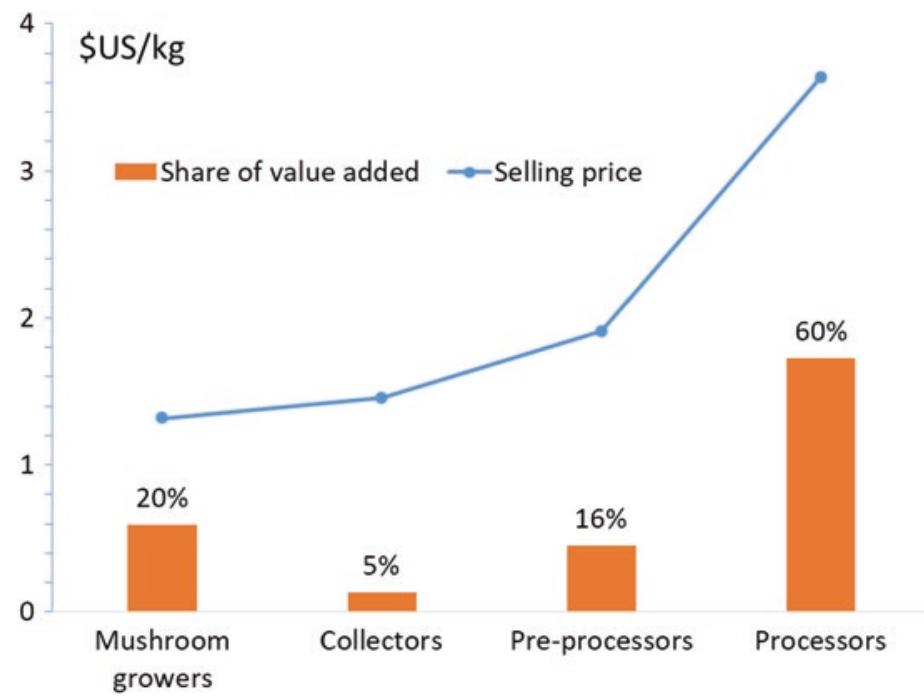

Fig. 11.5 Shares of value-added and selling prices by actors along processed-RSM value chains in MRD, Vietnam, in 2015-2016. (Adapted from Toan (2018) and Truc et al. (2017))

The contributions (shares) of actors along two RSM value chains to the total valueadded are presented as percentages (orange bars in the two figures).

For fresh-RSM value chains, over one-third of the value-added is generated by the mushroom growers (1.20 US\$ kg-1, representing $41 \%$ of the total share of value-added of fresh RSM). The remaining share of value-added mainly derives 
from transportation of RSM by the collectors and local wholesalers. However, fresh mushrooms are transported from production sites to the end users (located 100-300 km away) using simple preservation techniques, if any. As a result, fresh mushrooms degrade very fast (and should be consumed within a day). For processed RSM, processors are the actors who contribute and capture the largest share (75\%) of the total value-added.

Although mushroom farmers generate high value-added in fresh-RSM value chains, they are often exposed to high levels of risk due to unstable yields and selling prices of fresh mushroom. Between 15\% and 45\% of RSM growers in Can Tho, Dong Thap and Hau Giang provinces in the MRD experience losses (Truc et al. 2017). The main risks in RSM production are unfavorable weather (for outdoor RSM growing), spawn contamination, and straw and water quality (see more details in Chap. 6).

The same case applies to processors, who contribute and capture the highest share of the value-added in processed-RSM value chains. They are also the only actors directly exposed to various risks associated with exporting RSM. The main challenge in their business is to ensure quality and traceability of processed RSM to comply with exporters' requirements. However, as processors procure fresh and preprocessed mushroom in open markets from collectors and preprocessors, they are often unable to trace inputs and mushroom sources, which are among the most important factors in quality control. In addition, they face changing consumers' preferences as well as changes in technical requirements of exporters.

Wholesalers generate the lowest share of value-added (11\%) in the fresh-RSM channel. However, wholesalers earn daily profits of around US\$ 1000-2000, while RSM growers make less than US\$100 (which amounts to approximately US\$ 6000 for each two-month cycle of mushroom growing); some even experience financial losses.

The significant profit gap between wholesalers and growers is caused by (1) the high perishability of fresh RSM (putting the growers under the pressure of having to sell the product as quickly as possible, even at lower prices); (2) the economies of scale for wholesalers who trade in bulk, as opposed to individual growers who sell mushrooms in small quantities; and (3) the larger markets that wholesalers can access (e.g., big cities), as opposed to farmers with limited market access.

\subsubsection{Stakeholder Analysis}

Stakeholder analysis reveals the linkages, relationships, roles, and influence of RSM stakeholders in the subsector. To conduct stakeholder analysis, key agents from RSM value chains were first identified (maximum ten agents). Second, they were ranked in terms of their importance and influence $(1=$ least importance or influence and $10=$ highest importance or influence). "Importance" relates to the priorities given to satisfying needs and interests of each stakeholder. It is also their position or importance in relation to other actors/stakeholders based on their power, 


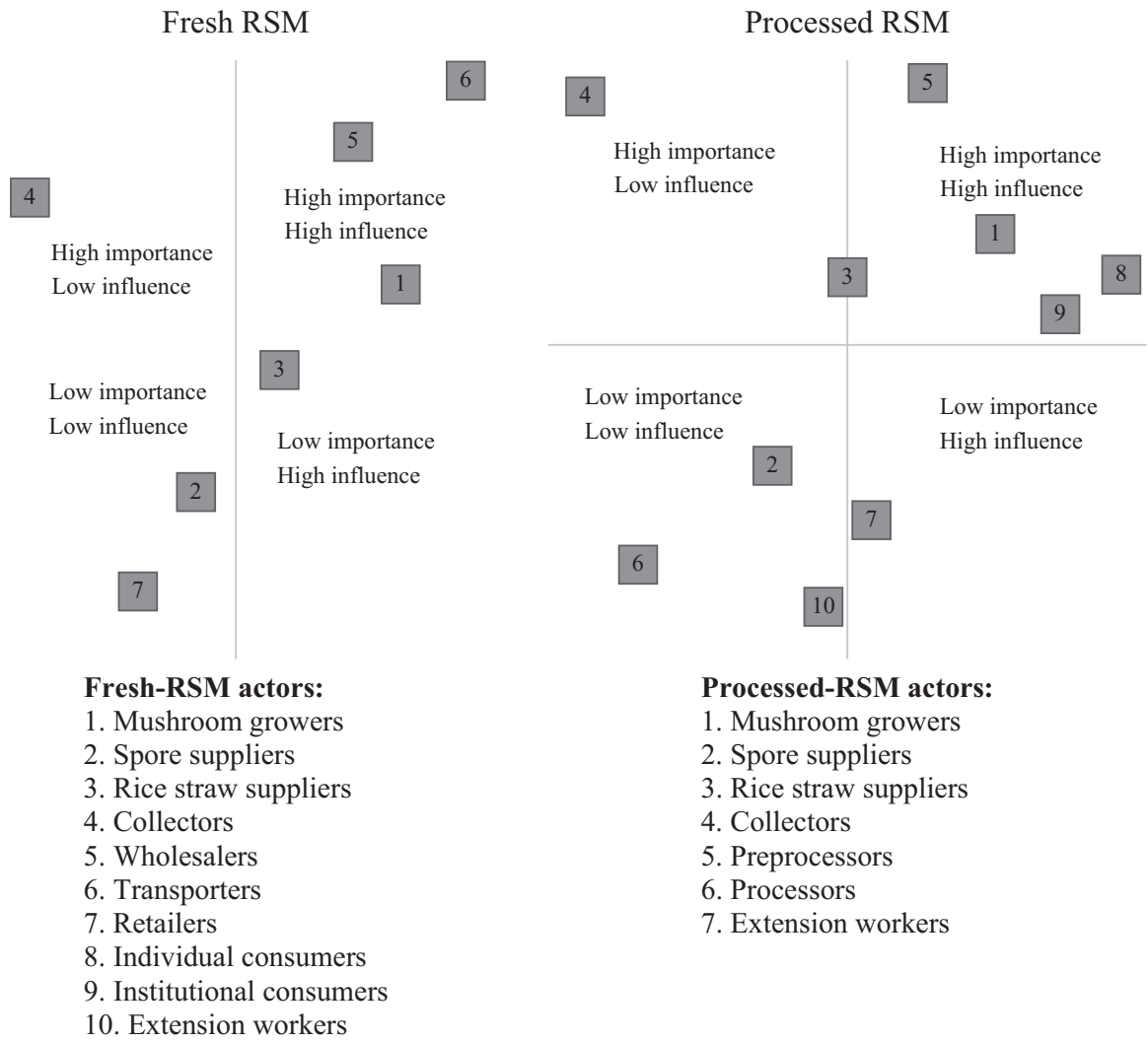

Fig. 11.6 Importance-influence matrix of RSM in the MRD

which is stipulated by trading capacity, quantity, quality, and price management in the current market. "Influence" relates to the power of a stakeholder to facilitate or impede the achievement of an activity's objective. In this analysis, the criterion used to evaluate the influence of the stakeholders was their contribution to the success of expanding the RSM subsectors (including increasing both volume and sales). Then, the ranked agents were mapped in the importance-influence matrix (Fig. 11.6).

The stakeholder analysis was first conducted by the research team using data from interviews of individual actors. Then, it was verified in a multi-stakeholder workshop in which importance and influence were assessed.

In the fresh-RSM market, wholesalers in Can Tho, Dong Thap, and Binh Dien are the most important players. They set or influence the price of mushroom on the market on a daily basis because they know who will consume the fresh product. Extension workers and transporters have the least important roles in both the fresh and processed-RSM value chains. 
In order to expand RSM production for the fresh market, extension workers should engage more with other agents to improve productivity and value-added by speeding up the transfer of production, trading, and processing technologies. Transporters and collectors could increase their role and strengthen their links with mushroom growers and local wholesalers. Otherwise, transport should be integrated into wholesalers' business models leading to fewer intermediaries in the value chain with stronger linkages ("dis-intermediation"; see Reardon et al. 2014; Reardon 2015).

To expand the processed-RSM market, processors need to further explore the demand for processed products in the domestic and overseas markets. Moreover, the expansion of both the fresh and processed-RSM markets requires collaboration and linkages between agents to govern the traceability and quality of inputs (straw and spore), straw mushroom-growing practices (increase productivity and safety) and preprocessing and processing procedures (safe and good practices) to meet increasingly strict market requirements. More research on the demand of new products and consumer behavior in export markets will help expanding those markets.

\subsubsection{Constraints of RSM Value Chains}

\subsubsection{Low Economic Returns and High Risks}

The first constraints in RSM value chains are the low economic returns and high risks involved in the business. In the domestic fresh-RSM market, growers generate the highest value-added along the fresh-RSM value chain; however, they receive lower daily profits compared to other actors. Growers are applying traditional methods to produce RSM (open-field practices). This leads to low yields, high investment costs, and environmental risks. Fresh mushroom is not preserved properly during transportation from production sites to end-markets, leading to high damage and shorter shelf-life of products.

\subsubsection{Lack of Linkages among Actors}

This is one of the main challenges in most agricultural value chains in developing countries (Reardon et al. 2014; Reardon 2015). Processors are facing increasingly strict export requirements; but as they do not have reliable contract-based links with preprocessors, mushroom growers and input supplies, it is difficult for them to govern the traceability and quality of RSM production processes. From the perspective of the growers, since they are not strongly linked to input suppliers and traders, they are not well-informed about the characteristics and quality of the rice straw and the spawn that they use. Thus, it is difficult for growers to ensure quality inputs and, hence, govern product quality. 


\subsubsection{Little Support for Strengthening Capacity}

There is little support from external actors to strengthen the capacity of internal actors in RSM value chains. The main external actors, including local extension officers, researchers and financial providers, are not active in conducting and accelerating RSM-related research, technology transfer, and financial support to the value chain actors.

\subsubsection{SWOT Analysis}

We conducted a SWOT analysis to identify upgrading strategies for RSM value chains and explore opportunities for expanding the value chain subsector to divert the use of available rice straw in the MRD from burning to more value-added income opportunities. Table 11.1 provides a summary of the analysis.

Table 11.1 SWOT analysis of RSM value chain in MRD

\begin{tabular}{|c|c|c|}
\hline SWOT analysis & Strengths & Weaknesses \\
\hline & $\begin{array}{l}\text { 1. Available straw in } \\
\text { the MRD is abundant }\end{array}$ & $\begin{array}{l}\text { 1. Small-scale mushroom } \\
\text { production and trading }\end{array}$ \\
\hline & $\begin{array}{l}\text { 2. Available mushroom } \\
\text { growers, input } \\
\text { suppliers and buyers } \\
\text { with experience }\end{array}$ & $\begin{array}{l}\text { 2. Low economic return and } \\
\text { risky business }\end{array}$ \\
\hline & & $\begin{array}{l}\text { 3. Few linkages among } \\
\text { RSM actors }\end{array}$ \\
\hline & & $\begin{array}{l}\text { 4. Low quality of input } \\
\text { supplies }\end{array}$ \\
\hline Opportunities & S-O strategies & O-W strategies \\
\hline $\begin{array}{l}\text { 1. High demand for both fresh } \\
\text { and processed mushroom from } \\
\text { domestic and export markets }\end{array}$ & $\begin{array}{l}\text { Expand the mushroom } \\
\text { subsector in both size } \\
\text { and quality }\end{array}$ & $\begin{array}{l}\text { 1. Improve the efficiency of } \\
\text { the RSM subsector. }\end{array}$ \\
\hline $\begin{array}{l}\text { 2. Support from the } \\
\text { Vietnamese government to } \\
\text { expand the RSM subsector }\end{array}$ & & $\begin{array}{l}\text { 2. Improve linkages among } \\
\text { mushroom actors to improve } \\
\text { efficiency, quality, and scale }\end{array}$ \\
\hline \multicolumn{3}{|l|}{$\begin{array}{l}\text { 3. New technologies to } \\
\text { improve the performance of } \\
\text { RSM value chains }\end{array}$} \\
\hline Threats & S-T strategies & W-T strategies \\
\hline $\begin{array}{l}\text { 1. Increasing technical } \\
\text { restrictions from export } \\
\text { markets }\end{array}$ & $\begin{array}{l}\text { Improve the quality } \\
\text { governance and } \\
\text { efficiency of RSM } \\
\text { value chains }\end{array}$ & $\begin{array}{l}\text { Control and improve the } \\
\text { quality of input supplies as } \\
\text { well as mushroom products } \\
\text { and value chain processes. }\end{array}$ \\
\hline $\begin{array}{l}\text { 2. Higher cost of straw, labor } \\
\text { and land }\end{array}$ & & \\
\hline
\end{tabular}




\subsubsection{Strengths}

- Rice straw in the MRD is abundant without any specific utilization. About $40-80 \%$ of the rice straw in the MRD is still burned, especially in three rice cropping systems.

- Available mushroom growers, input suppliers and RSM buyers (straw and spore suppliers, transporters, wholesalers, retailers) with long experience working in the RSM subsector for 10-30 years. They will be valuable resources in supporting the expansion of the value chains.

\subsubsection{Weaknesses}

- Small-scale and individual mushroom production and trade that hinder mushroom growers, input suppliers and traders from engaging in large orders for mushroom products with specific and strict quality requirements.

- Low economic return and risky business due to low adoption of advanced techniques and technologies from production to transportation of fresh mushroom.

- Few linkages among RSM actors.

- Low quality of input supplies (straw and spores).

\subsubsection{Opportunities}

- High demand for RSM in both domestic and processed markets, especially the demand for safe, healthy and convenient products.

- The Vietnamese government supports the expansion of the RSM subsector and has issued policies and directions for its development.

- The availability of new technologies supporting the RSM subsector (production, transportation, and preservation).

\subsubsection{Threats}

- Increasingly strict technical requirements and standards in export markets as the latter have shifted from low-income (China, Taiwan, Hong Kong) to high-income markets (United States, Europe, Japan).

- Rising costs of straw, labor, and land.

\subsubsection{Recommended Strategies to Upgrade RSM Value Chains in the MRD}

From the SWOT analysis (Table 11.1), two recommended strategies to upgrade RSM value chains in the MRD are summarized below. 
- Improve the efficiency of the mushroom subsector. Explore and adopt new technologies that can reduce costs of straw collection and spore and RSM production as well as product preservation and processing.

- Improve the linkages among RSM value chain stakeholders to upgrade and expand the value chains. The purpose of linkages is to improve the efficiency and ensure the quality of mushroom products. Both RSM quality and quantity should be governed. Wholesalers and exporters should take the leading roles in linking the growers and other input suppliers.

\subsubsection{Recommended Prioritized Activities to Support Fresh and Processed Mushroom Value Chains}

- Enhance value chain linkages between rice farmers (who supply straw), mushroom growers, supporting actors (input suppliers, labor), and external agents.

- Transfer indoor mushroom growing techniques and other improved techniques to growers to improve productivity and profit from RSM production.

- Conduct market research to explore new market opportunities for fresh and processed mushroom products in the domestic and export markets.

\subsection{Summary, Further Research, and Developments}

RSM value chains have been adapted and improved over the last 40 years. However, the profit margin for actors is still low and participation in RSM value chains involves a high level of risks. Mushroom growers are facing many difficulties, such as the lack of a reliable supply of good quality of straw and spawn. Mushroom yield is low and fluctuates ( $0-4 \%$ of rice straw use) due to the fact that it is mostly produced outdoors. Mushroom growers are still reluctant to shift and invest in improved mushroom production techniques and indoor models.

Speeding up technology expansion and controlling straw and spawn quality will significantly improve profits for mushroom growers. Enhancing the linkages and coordination along the value chains will improve their overall performance and foster upgrading. Improving fresh-mushroom transportation systems will enhance mushroom quality. Finally, sound market research to explore new opportunities for fresh and processed-mushroom products is needed to inform actors and crowd-in investment in value chain upgrading.

Value chains and influencing factors of rice straw in Vietnam, Cambodia, and the Philippines were mapped through multi-stakeholder workshops with experts from agriculture and the food and energy sectors. In terms of future markets for agricultural uses, Vietnamese and Cambodian stakeholders proposed organic fertilizer, crop mulching, and biochar, while Philippine stakeholders suggested rice straw nets/mats, rice straw gardens, and seedling pots and trays for mechanical rice trans- 
planters. For future food and feed markets, stakeholders from all three countries agreed that animal feed is the most promising product. Cambodian stakeholders also saw potential in mushrooms as a future opportunity that needs to be developed. When looking at future markets for energy and industry, Vietnamese and Cambodian stakeholders identified bioplastics and biofuels as the most promising, whereas Philippine experts suggested biofilters/desiccants, nanomaterials, and textiles.

Investment in product and technology development and quality upgrading were identified to be the main upgrading strategies required to develop rice straw value chains in the three countries. Investment in rice straw value chain upgrading should be preceded by proper end-market analysis to assess consumer acceptance of the new products that are derived from rice straw.

The current rice straw "supply" chains observed in the three countries are short and supply-driven. All three are on a similar trajectory of intersectoral upgrading with Vietnam leading, closely followed by Cambodia and the Philippines lagging behind. However, Philippine stakeholders identified a great diversity of future endmarkets and products. The rich data obtained through the stakeholder workshops in the three countries indicate that many market opportunities for rice straw are still untapped and more R\&D will be needed to develop these opportunities. The more these markets are developed, the more rice straw will evolve into a commodity with increasing market value, and the more farmers will receive monetary (and nonmonetary) incentives to move away from straw burning towards more sustainable uses of rice straw.

\section{References}

FAO (2014) Developing sustainable food value chains: guiding principles. Food and Agriculture Organization of the United Nations (FAO), Rome. http://www.fao.org/3/a-i3953e.pdf

Gereffi G (1999) International trade and industrial upgrading in the apparel commodity chain. J Int Econ 48(1):37-70

IRRI (International Rice Research Institute) (2019) Final report of the BMZ-funded IRRI sustainable rice straw management project (unpubl.)

Kaplinsky R, Morris, M (2000) A handbook for value chain research (Vol. 113). University of Sussex, Institute of Development Studies

Nguyen VH, Nguyen CD, Van Tran, T, Hau HD, Nguyen NT, Gummert M (2016) Energy efficiency, greenhouse gas emissions, and cost of rice straw collection in the Mekong River Delta of Vietnam. Field Crop Res 198:16-22

Nguyen VH, Balingbing C, Quilty J, Sander BO, Demont M, Gummert M (2017) Processing rice straw and husks as coproducts. In: Sasaki $\mathrm{T}$ (ed) Achieving sustainable rice cultivation. Burleigh Dodds Science Publishing Limited, Cambridge, pp 1-33

Reardon T (2015) The hidden middle: the quiet revolution in the midstream of agrifood value chains in developing countries. Oxf Rev Econ Policy 31(1):45-63

Reardon T, Chen KZ, Minten B, Adriano L, Dao TA, Wang J, Das Gupta S (2014) The quiet revolution in Asia's rice value chains. Ann N Y Acad Sci 1331:106-118

Toan DM (2018) Mushroom value chain in Dong Thap Province, Vietnam. Masters thesis. Can Tho University. In: Vietnam 
Truc NTT, Sumalde ZM, Palis FG, Wassmann REINER (2013) Farmers' awareness and factors affecting farmers' acceptance to grow straw mushroom in Mekong River Delta, Vietnam and Central Luzon, Philippines. Intl J Environ Rural Dev 4(2):179-184

Truc NTT, Toan DM, Hung PQ (2017) Including gender issues and value chain analysis to develop straw mushroom production in the Mekong River Delta: Case study Vinh Loi District, Bac Lieu Province. Research Report. CCAFS-IRRI

Wang H, Moustier P, Nguyen TTL (2014) Economic impact of direct marketing and contracts: the case of safe vegetable chains in northern Vietnam. Food Policy 47:13-23

Open Access This chapter is licensed under the terms of the Creative Commons Attribution 4.0 International License (http://creativecommons.org/licenses/by/4.0/), which permits use, sharing, adaptation, distribution and reproduction in any medium or format, as long as you give appropriate credit to the original author(s) and the source, provide a link to the Creative Commons licence and indicate if changes were made.

The images or other third party material in this chapter are included in the chapter's Creative Commons licence, unless indicated otherwise in a credit line to the material. If material is not included in the chapter's Creative Commons licence and your intended use is not permitted by statutory regulation or exceeds the permitted use, you will need to obtain permission directly from the copyright holder.

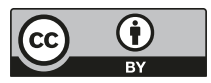

